\title{
Middle-School Student Engagement in a Tick Testing Community Science Project
}

\author{
Amy Prunuske ${ }^{1, *}$, Cole Fisher ${ }^{2}$, Jhomary Molden ${ }^{3}{ }^{\oplus}$, Amarpreet Brar $^{3}$, Ryan Ragland ${ }^{4}$ and Jesse vanWestrienen ${ }^{4}$ \\ 1 Department of Microbiology and Immunology, Medical College of Wisconsin-Central Wisconsin, \\ Wausau, WI 54401, USA \\ 2 Department of Biomedical Sciences, University of Minnesota Duluth, Duluth, MN 55812, USA; \\ nfisher@d.umn.edu \\ 3 Department of Biology, University of Wisconsin Stevens Point, Stevens Point, WI 54481, USA; \\ jhomary22@gmail.com (J.M.); amarbrar11@gmail.com (A.B.) \\ 4 Biomeme, Philadelphia, PA 19107, USA; ryan.lee.ragland@gmail.com (R.R.); jesse@biomeme.com (J.v.) \\ * Correspondence: aprunuske@mcw.edu
}

Citation: Prunuske, A.; Fisher, C.; Molden, J.; Brar, A.; Ragland, R.; vanWestrienen, J. Middle-School Student Engagement in a Tick Testing Community Science Project. Insects 2021, 12, 1136. https://doi.org/ $10.3390 /$ insects 12121136

Academic Editors: Marco Salvemini and Koichi Goka

Received: 9 October 2021

Accepted: 17 December 2021

Published: 18 December 2021

Publisher's Note: MDPI stays neutral with regard to jurisdictional claims in published maps and institutional affiliations.

Copyright: (c) 2021 by the authors. Licensee MDPI, Basel, Switzerland. This article is an open access article distributed under the terms and conditions of the Creative Commons Attribution (CC BY) license (https:/ / creativecommons.org/licenses/by/ $4.0 /)$.
Simple Summary: Lyme disease is a common tickborne illness endemic to many countries, including the United States. Scientists have a role to play in disseminating public health knowledge to decrease the prevalence of tickborne disease, which can include encouraging preventive behaviors and recognizing the early signs of the disease. Middle-school students are at significant risk of developing Lyme disease and an ideal population to engage in community-based science, since these experiences provide valuable opportunities for career explorations and to extend the students' understanding of science. Our work shows that the students can meaningfully contribute to research by generating samples that can be used to test whether the ticks contain pathogens.

Abstract: Studies of tickborne illness have benefited from interactions between scientists and community members. Most participants in community science projects are well-educated adults, but there are anticipated benefits from engaging younger students in research. We evaluated whether an outreach experience for rural middle-school students promoted student interest in science and resulted in the generation of samples that could be used for tick testing to assess disease risk. Middle-school students from 78 Wisconsin communities developed interdisciplinary hypotheses about the spread of Lyme disease, identified ticks, and extracted DNA from ticks to assess the prevalence of pathogens Borrelia burgdorferi, Anaplasma phagocytophillium, and Babesia microti. As a result of this intervention, students were able to successfully complete the research protocol and explain the rationale for completing the experiment. Of student participants, $84.7 \%$ reported no difficulty completing the protocol, $66 \%$ of the student samples gave reliable PCR results, and $76 \%$ of students reported interest in participating in similar experiments. Our study shows that tick outreach programs that incorporate community-based science promote knowledge about Lyme disease, facilitate engagement between students and scientists, and generate samples that can be successfully utilized for pathogen testing.

Keywords: citizen science; Lyme disease; Ixodes scapularis; tick; Borrelia burgdorferi; community science; Anaplasma phagocytophilium; Babesia microti

\section{Introduction}

In the 1970s, two mothers from Lyme, CT collected local data that they shared with scientists leading to the discovery of Lyme disease [1]. This demonstrated a role for citizen or community science, which has only grown in recent years and facilitates the generation of data by amateur collectors [2]. In Wisconsin, Lyme disease is transmitted through tick vector Ixodes scapularis, and there is growing concern about the prevalence of $I$. scapularis carrying not only Lyme disease pathogen Borrelia burgdorferi, but also pathogens Babesia microti and Anaplasma phagocytophila [3]. Assessing the risk of tickborne illness 
through environmental surveillance fits under the One Health model that requires a holistic understanding of how the environment, animal health, and human health form a connected public health web [4]. New opportunities for community science are facilitated by the invention of portable scientific tools coupled to mobile technology that support the testing of samples for pathogens outside of the laboratory. These technologies support wider and more inclusive participation in science, but raise questions about the reliability of community-generated data and analysis as compared to experiments completed by trained scientists.

Community engagement is strengthened when tied to local context, which is why we developed community science presentations focused on tickborne diseases targeted at rural middle-school students. Middle-school students were selected as the target population since they are a high-risk group for the development of tickborne illness [5]. Middle school is also a time when students are beginning to explore careers and could benefit from engagement in the practice of science, including developing hypotheses and completing experiments. These types of experiences help students in building their science identities or core sense of the value of science [6]. Many rural students have never met a scientist and are unfamiliar with the pathway to garnering an advanced degree in science [7]. A potential challenge in using middle-school students is the variability in their prior experience completing scientific protocols.

Attending a Lyme disease outreach presentation had helped students in increasing their knowledge of Lyme disease and ability to recognize ticks that transmit Lyme disease [8]. We next wanted to determine whether students could successfully extract DNA from ticks to be used as part of a community science research project designed to characterize the prevalence of the pathogens in ticks from Wisconsin. This experiment was designed for optimal learning by considering the middle-school audience, adopting purposeful activity, incorporating social interaction, and optimizing activities on the basis of participant feedback [9]. To evaluate the effectiveness of the intervention, we characterized who participated in the project, viewed videos of students completing the DNA extraction protocol, assessed the student understanding of why the procedure was completed, and determined the percentage of samples that generated usable research results.

\section{Materials and Methods}

\subsection{Evaluation of Tick Outreach Sessions}

Presentations were primarily held at the University of Wisconsin-Stevens Point as part of Science Technology Engineering and Math and College for Kids outreach events held in 2017-2019, targeting middle-school students aged 11-14 years. Three to four sessions were delivered in a day for groups of 20-25 students. A faculty member and 1-2 undergraduates delivered the interactive session, giving middle-school students the opportunity to answer multiple-choice polling questions and to ask their own questions about Lyme disease. Participants were asked to hypothesize what might contribute to changing the epidemiology of tickborne illnesses in Wisconsin and to discuss how to test their hypotheses, including by testing the ticks for pathogens. Then, the middle-school students extracted DNA from ticks to generate samples, and the presenter emphasized that the undergraduates would analyze their samples with a portable RT-PCR device. After completing the activity, students completed a reflection worksheet (Supplemental Materials) which was reviewed and independently coded by the faculty member and an undergraduate to identify broad themes that were discussed and refined using a grounded theory approach.

Google Maps (https:/ /www.google.com/maps/, accessed on 26 February 2019) was used to show the distribution of schools participating in the presentation. For a subset of the presentations, we collected consent forms from parents to review videos of the students completing the DNA extraction protocol. The faculty member and undergraduates collaborated to identify student errors that had been observed and behaviors that supported 
the successful completion of the DNA extraction. The protocol was approved by the Institutional Review Board of Medical College of Wisconsin (PRO00029271).

\subsection{Tick Identification}

Undergraduates assisted the middle-school students in identifying the ticks and served as role models by sharing with students their own path to their undergraduate degree [10]. In groups of 2-4, the middle-school students used a tick key (Minnesota Department of Health) to identify the species and sex of a tick. Community members removed the ticks from dogs through passive surveillance or, prior to the session, undergraduates engaged in active flagging using drag cloths, which led to the generation of a geographically and temporally diverse tick bank, and the researchers noted any relevant travel history. Ticks were stored in a $1.5 \mathrm{~mL}$ Eppendorf tube containing $750 \mu \mathrm{L}$ of alcohol-based hand sanitizer (at least $60 \% \mathrm{w} / \mathrm{v}$ in water) at $-20{ }^{\circ} \mathrm{C}$ so that they would not dry out prior to the middle-school students' analysis. The faculty member generated an ID number, and recorded the species, sex, and location where the tick was collected prior to the session to ensure that we had accurate data for our records. Most of the ticks selected for testing were I. scapularis, the predominant vector for transmission, and a small subset of students viewed Dermacentor virabilis, the other tick species that is commonly found in Wisconsin. The students took pictures of their ticks and the corresponding ID number using iPads (Figure 1). Students utilized personal protection, including gloves and safety googles. The faculty member emphasized to the participants that the ticks were dead, and that transmission requires the ticks to be attached to the host for an extended period of time.

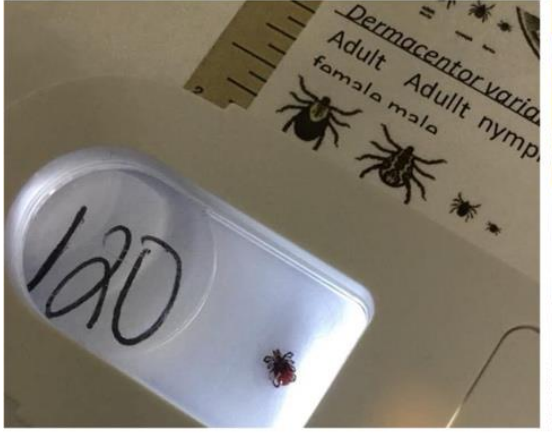

(a)

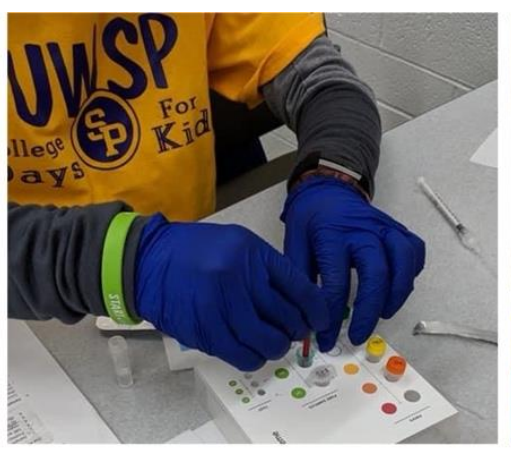

(b)

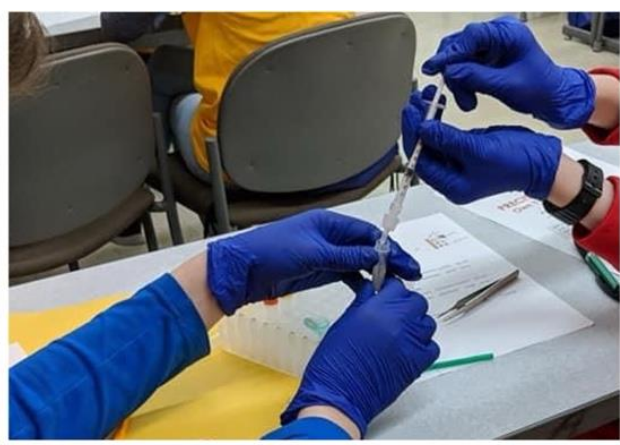

(c)

Figure 1. Students identifying tick species and performing DNA extraction. (a) Students identify an adult female I. scapularis using a magnifying glass. (b) Students use a pestle to crush tick in the lysis buffer. (c) Students use a syringe to purify the DNA.

\subsection{Extracting DNA from Ticks}

The DNA of adult ticks and any pathogens it contained were extracted by the participants using a lysis protocol developed by Biomeme, Philadelphia, PA [11]. A written protocol was provided to the participants, and the procedure was completed by the faculty member or an undergraduate at the front of the classroom. A subset of students recorded their groups carrying out the protocol using the same iPad that they used to take pictures of the ticks. The first step in the DNA extraction protocol was to disrupt the tick cellular material by using a pestle in a lysis buffer, releasing the DNA from the cells (Figure 1). The crushed tick is allowed to settle to the bottom of the lysis buffer tube. The liquid containing the DNA was drawn up with a $1 \mathrm{~mL}$ syringe attached to a column containing a silica membrane that selectively binds the DNA, and pushed back out. This was repeated for 10 pumps. The column was washed to remove unwanted cellular material with a protein wash, wash buffer to remove salts, and drying buffer (1 pump each). Lastly, the column was air-dried (20 pumps). and the purified DNA was eluted off the membrane as part of the final step (5 pumps). 


\subsection{Real-Time PCR Assay}

After the presentation in the laboratory, the undergraduates added $20 \mu \mathrm{L}$ of the purified DNA to each of 3 wells containing lyophilized primers, 2 fluorescent probes (SYBR/Cy5), and a master mix. The assay allows for confirmation of the tick species by testing for I. scapularis, D. variabilis, and A. americanum, and to test for most prevalent tickborne pathogens B. burgdorferi, A. phagocytophilum, and B. microti. Species identification through PCR was used as a positive control, since the tick species for each sample was known. The test strip was placed in the portable Biomeme two3, a thermocycler attached to an iPhone [11]. Samples are initially denatured for $1 \mathrm{~min}$ at $95^{\circ} \mathrm{C}$, then denatured for $1 \mathrm{~s}$ at $95^{\circ} \mathrm{C}$, and annealed for $20 \mathrm{~s}$ at $60^{\circ} \mathrm{C}$ for 45 cycles. The cycle threshold $(\mathrm{Ct}$ ) was determined, and data were then uploaded to an online portal. Strategies to prevent DNA contamination of samples included using lyophilized reagents, decontaminating surfaces with $70 \%$ ethanol, using aerosol-resistant filtered pipette tips, not opening tubes containing the amplified product, and properly disposing of all tubes [12].

\subsection{Real-time PCR Confirmation}

Data collected with the Biomeme device were verified using the Roche LightCycler ${ }^{\circledR}$ 480 instrument (software version LCS480 1.5.0.39; Roche Diagnostics, Mannheim, Germany). RT-PCR reactions were conducted in LightCycler ${ }^{\circledR} 480$ Multiwell Plate 96, white plates (Roche Diagnostics, Mannheim, Germany). Total reaction volumes of $20 \mu \mathrm{L}$ comprised up to $8 \mu \mathrm{L}$ of DNA, either $10 \mu \mathrm{L}$ Biomeme MasterMix or $1 \times$ LightCycler $^{\circledR} 480$ Probes $^{\circ}$ Master (Roche Diagnostics, Mannheim, Germany), either $1.0 \mu \mathrm{L}$ A. phagocytophilum-CY5 probe or B. microti-CY5 probe, $1.0 \mu \mathrm{L}$ B. burgdorferi-FAM probe, and PCR-grade water. The LightCycler ${ }^{\circledR} 480$ instrument standard factory template for Dual Hydrolysis ProbeUPL Probe 96-II settings with FAM $(465-510 \mathrm{~nm})$ and CY5 $(618-660 \mathrm{~nm})$ were used to program assay parameters. Initial enzyme activation was set at $95^{\circ} \mathrm{C}$ for $10 \mathrm{~min}$, followed by 45 cycles of amplification run at $95^{\circ} \mathrm{C}$ for $10 \mathrm{~s}, 60^{\circ} \mathrm{C}$ for $30 \mathrm{~s}$, and $72{ }^{\circ} \mathrm{C}$ for 10 s. The assay was completed with a cooling cycle at $40{ }^{\circ} \mathrm{C}$ for $30 \mathrm{~s}$. Known samples of B. burgdorferi, A. phagocytophilum, and B. microti DNA were utilized as positive controls. Roche LightCycler ${ }^{\circledR} 480$ instrument software Abs Quant/2nd Derivative Max was used to calculate the Ct value.

\section{Results}

The objectives of the Lyme disease community science session were to expose middleschool students to science careers, to analyze information about tick biology and Lyme disease, and to generate DNA samples for tick testing (Figure 2a). Over 400 middleschool students (age 11-14 years) participated in the session with approximately equal participation by gender. By partnering with a local university, we were able to reach a wide geographic distribution of middle-school students from 78 different schools and all from small metropolitan areas of fewer than 150,000 residents (Figure 2b). This included students from groups under-represented in science, including the Menominee Indian Nation, Stockbridge-Munsee Community band, and Hmong refugees. Middle-school students then worked with the undergraduates to take pictures of the tick, to identify the tick species, and to extract DNA (Figure 1). Capturing high-quality images was one aspect that was optimized over the program, first utilizing magnifying glasses, and ultimately benefitting from improved cameras in the more recent iPad models. Students developed hypotheses about why the number of tickborne illnesses has been increasing in NorthCentral Wisconsin, and completed a reflective worksheet at the end of the session to check if students understanding the goal of the experiment (Supplemental Methods). 


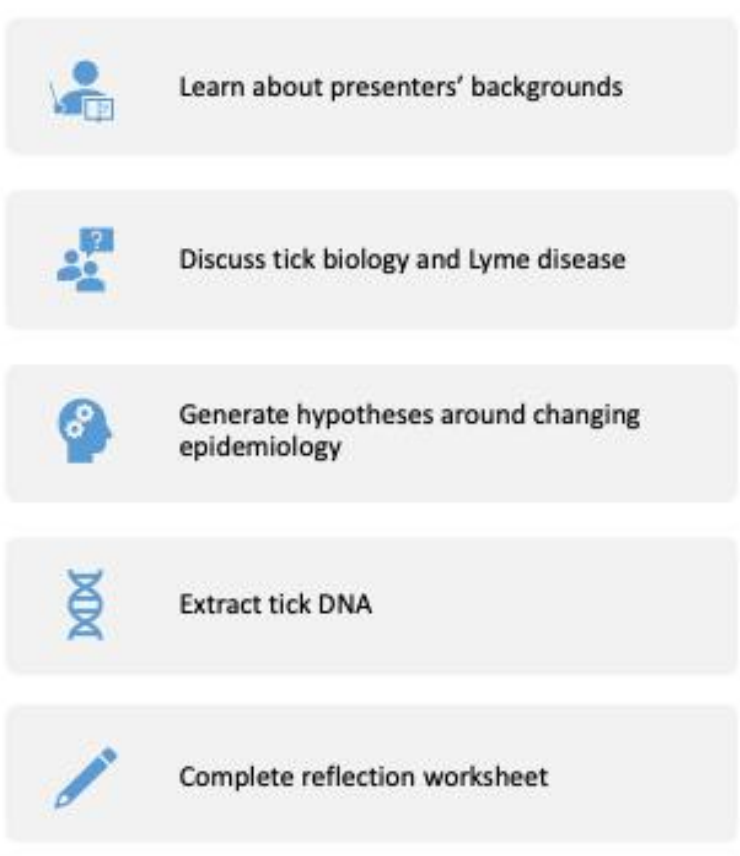

(a)

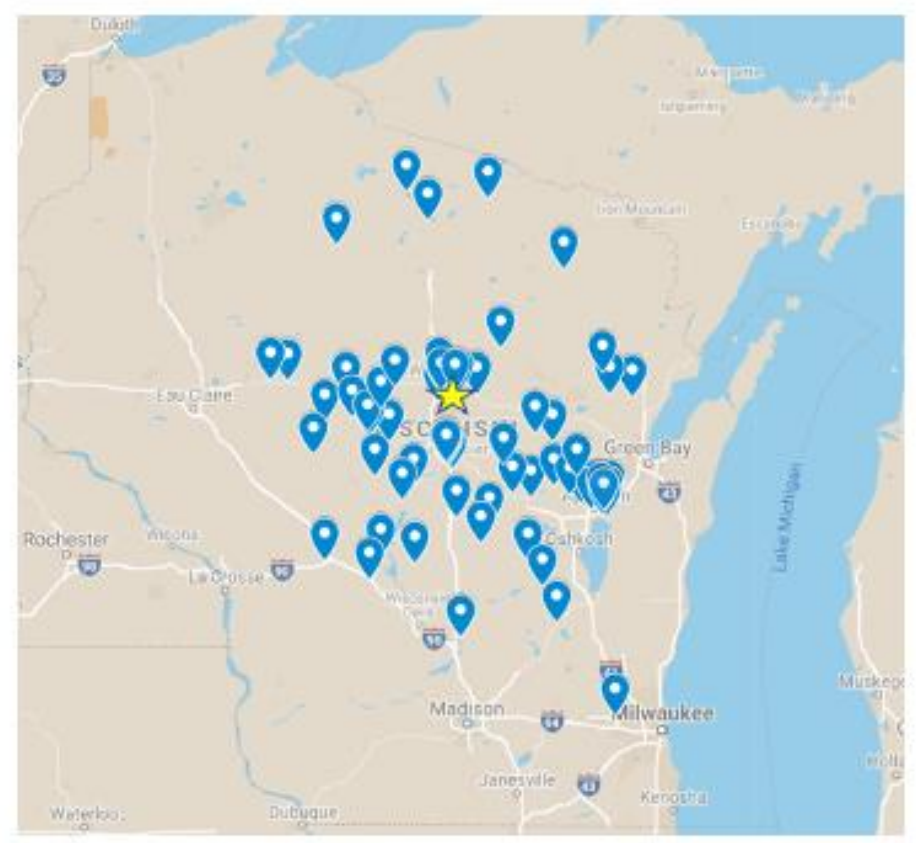

(b)

Figure 2. Middle-school community science session incorporated students from across the state. (a) Description of activities that were included in the session. (b) Map displaying the location of the schools that participated in the outreach activity. Star indicates the location of the university that hosted many of the presentations.

We reviewed 10 videos of student teams completing the DNA extraction protocol. It took the students 10-15 min to complete the DNA protocol as a group of 2-4 students. Students were given a written protocol, but very few students were observed looking at the written protocol, with most following along with the presenter at the front of the classroom. Students worked in groups, and often asked each other and the undergraduates for clarification: "So what do you do after?" and "Is there DNA in every single one of these (the tubes)?" Often, one student would open and close the tubes, while the other pumped or the participants took turns performing the steps, so there was active engagement of all participants. Students made relevant observations, including discussing the presence of a white precipitate on the pestle, the smell of the ethanol in one of the reagents, and noticing differences in the shape of the reagent tubes because of differences in the volume of liquid they contained. Students also corrected each other. In one case, a student was trying to use the pipette instead of the pestle to crush the tick: "This is actually what we are supposed to use." Most of the students appeared to have completed each of the steps in the protocol and avoided contamination of the samples.

Students were asked on the worksheet to indicate whether they had trouble completing the DNA extraction protocol, and $84.7 \%$ reported no difficulty completing the protocol (Table 1). Students indicated "Not really, you just needed to follow directions." The students had the most challenges with crushing the tick due to the tough carapace, and we stopped using nymphs since they were harder for the students to transfer due to their small size. The greatest challenges were spilling the sample and using the buffers in the wrong order. Some students did not completely expel the liquid before moving on to the next tube and instead transferred liquid between tubes, potentially diluting the buffers and negatively impacting yield. The presenters began to emphasize the importance of fully expelling the sample before moving on to the next tube. It was also helpful to prelabel the tubes to ensure that the undergraduates could correctly match up the samples after the presentation. 
Table 1. Summary of reflection worksheet.

\begin{tabular}{cccc}
\hline Statement & Yes & Maybe & No \\
\hline $\begin{array}{c}\text { 1. Trouble completing the protocol } \\
n=308\end{array}$ & $13.6 \%$ & $1.6 \%$ & $84.7 \%$ \\
$\begin{array}{c}\text { 2. Interest in participating in another } \\
\text { community science project } \\
n=117\end{array}$ & $76.1 \%$ & $8.5 \%$ & $15.3 \%$ \\
$\begin{array}{c}\text { 3. Interest in a career in science } \\
n=267\end{array}$ & $47.5 \%$ & $14.2 \%$ & $38.3 \%$ \\
\hline
\end{tabular}

When students were asked on the worksheet "Why did you complete the DNA extraction protocol?", 58.6\% understood that the goal was "to test whether the tick can transmit Lyme disease"; some went further: "wanted to figure out if ticks could kill us". Of the students, $14.3 \%$ responded that they had completed the experiment "because you told us to". Other answers included more aspirational ideas, because "it was fun and interesting", "we wanted to advance science", or because "I want to work in the medical field". In addition, $76.1 \%$ indicated they would like to participate in another community science project while only $47.5 \%$ indicated they were interested in a career in science. "I'm not sure because I love doing different experiments, but I don't know if I want that to be my job." Students were unsure of how science might fit with their future career progression, and indicated not being interested in a science career even when there was a high likelihood that their career interest would require some science familiarity (i.e., being a doctor or fishing guide). The second two statements were added to the reflection worksheets midway through the presentations, which is why the number of responses were slightly lower.

After the presentation, the samples generated by the middle-school students were tested for Borrelia burgdorferi, Anaplasma phagocytophilum, and Babesia microti by the undergraduates using the portable RT-PCR device. The assay also confirmed the tick species differentiated among Ixodes scapularis, Dermacentor varabilis, and Amblyomma americanum. Of the 92 tested Ixodes scapularis samples, 61 samples (67\%) successfully amplified Ixodes scapularis DNA. From the samples that were successfully amplified, $41 \%$ contained Borrelia burgdorferi DNA, 9.8\% contained Anaplasma phagocytophilum, and 4.9\% contained Babesia microti (Table 2). Results obtained with the portable RT-PCR device were confirmed with the Roche LightCycler, and these rates fell within the range of those that had been observed in previous studies in Wisconsin.

Table 2. Pathogen testing results. Percentage of adult ticks that tested positive for each of the pathogens from this study (Prunuske) and from similar studies conducted in Wisconsin (Stauffer and Westwood).

\begin{tabular}{cccc}
\hline & Prunuske $\mathbf{N = 6 1}$ & Stauffer $\mathbf{N}=\mathbf{3 6}$ [13] & Westwood $\mathbf{N}=\mathbf{4 6 1}$ [3] \\
\hline Borrelia burgdorferi & $41.0 \%$ & $52.8 \%$ & $17.4 \%$ \\
Anaplasma & $9.8 \%$ & $5.6 \%$ & $14.3 \%$ \\
phagocytophilum & $4.9 \%$ & $2.8 \%$ & $6.5 \%$ \\
Babesia microtii & & & \\
\hline
\end{tabular}

\section{Discussion}

By partnering with a local college, over 400 rural middle-school students had the opportunity to participate in a community science project and generate samples that contributed to a larger scientific effort. Several components of the design facilitated active bidirectional knowledge exchange, with participants not just learning from scientists about how to prevent tickborne disease, but also offering up their own hypotheses and experiences with Lyme disease. One of the advantages of community science is questioning pernicious assumptions about who is capable of participating in science [9]. Engagement with students from rural backgrounds is important, since rural students are less likely 
to have access to camps or informal science learning environments such as museums and to enroll in postsecondary science, technology, engineering, and mathematics (STEM) degree programs, compared with their suburban peers [14]. Empowering wider participant engagement in community science has the potential to increase community science literacy or the ability to use science to advance local community issues [9].

Key partnerships facilitated the authentic participation of students in the work of scientists. Others have highlighted the value of partnerships among universities, students, and teachers to successfully doing community-based work [15], but our work shows that incorporating industry partners adds additional value that can offset resource and logistical costs. Our evaluation demonstrated that community members can effectively process samples for accurate pathogen testing, which is important to avoid misleading conclusion. Our methods facilitated the identification of some design flaws in the DNA extraction kit that contributed to loss of the sample, resulting in new kits coming in cartridge format. Given our results showed that the portable RT-PCR device generated similar results to those of laboratory-based DNA testing, there is increased opportunity to engage additional community members in this technology, which has also become more relevant with the increase in DNA-based testing during the COVID-19 pandemic [16]. The company is developing a shared platform to integrate the results from around the world, allowing for participants to look up their individual results paired with visual data on a map [17]. Over the long term, this could be used to crowdsource the monitoring of geographic and temporal changes in the pathogens, and allow for participants to perform their own data analysis, which would require additional training and longer-term engagement between the scientist and a subset of students.

This study focused on middle-school students who volunteered to participate as part of a local college field trip. It is important to know your audience, and identify obstacles that might negatively impact motivation and limit the generalizability of the results. Others found that the majority of citizen science experiences for students do not meet next-generation standards with students struggling to understand why they are collecting data [18]. We aligned our activity with these standards, and the reflection worksheet allowed for students to articulate in their own words the purpose of the activity. Best practices for that age group included incorporating opportunities to utilize technology and interact with peers and near-peers (undergraduates). There may be tension between students having fun and ensuring that they generate samples of sufficient quality. Most of the samples resulted in amplification of the control target, but not all; so, we recommend that samples be processed by trained scientists if they are limited. Follow-up studies would support a better understanding of the long-term impact of the experience, and there could be more deliberate partnerships with teachers in the development of additional curricula. Others found that teachers that participate in insect outreach activities are subsequently much more interested in including insect-focused content [19].

Successful community engagement requires mutually beneficial partnerships, which was necessary for facilitating a large-scale community science endeavor [20]. Public engagement is encouraged for all federally funded research, and our work provides recommendations and strategies for scientists to utilize with middle-school students to advance scientific and participant goals.

Supplementary Materials: The following are available online at https:/ /www.mdpi.com/article/10 .3390 /insects12121136/s1, Figure S1: Handout used to assess student understanding of activity.

Author Contributions: Conceptualization, A.P.; methodology, R.R., A.P., J.v.; testing, J.M., A.B.; validation, C.F.; formal analysis, A.P.; data curation, J.M.; writing—original draft preparation, A.P.; writing-review and editing, C.F.; visualization, A.P.; funding acquisition, A.P. All authors have read and agreed to the published version of the manuscript.

Funding: This research was funded by an American Society for Cell Biology COMPASS outreach grant number and a Medical College of Wisconsin Small Device Equipment grant. 
Institutional Review Board Statement: The study was conducted according to the guidelines of the Declaration of Helsinki, and approved by the Institutional Review Board of Medical College of Wisconsin PRO00029271.

Data Availability Statement: The data presented in this study are available on request from the corresponding author.

Acknowledgments: The authors would like to thank Benjamin Clarke at University of Minnesota Medical School Duluth campus, Diane Caporale and Karin Bodensteiner at University of WisconsinStevens Point for the access to laboratory space, and Linda Cotton and Coda for the tick donations. We thank the following undergraduates who contributed to the project: Mona Alhala, Yang Vang, Netzali Pacheco Rojas, Nathan Lipinski, and Chao Yang. Thanks to the organizers of the College for Kids and STEM Outreach days for their assistance in recruiting participants, and to all the students who participated in the activity. Thanks to the Medical College of Wisconsin Community Engaged Mentoring Group and A.P.'s mentor, Syed Ahmed.

Conflicts of Interest: A.P. served as a developer for Biomeme and received materials from the company, but no additional compensation. J.W. is one of the founders of Biomeme and was not directly involved in the collection, analysis, or interpretation of the data. The funders had no role in the design of the study; in the collection, analyses, or interpretation of data; in the writing of the manuscript, or in the decision to publish the results.

\section{References}

1. Elbaum-Garfinkle, S. Close to Home: A History of Yale and Lyme Disease. Yale J. Boil. Med. 2011, 84, $103-108$.

2. Why We're Changing From 'Citizen Science' to 'Community Science,'” Audubon Center at Debs Park, 03 May 2018. Available online: https:/ / debspark.audubon.org/news/why-were-changing-citizen-science-community-science (accessed on 14 September 2021).

3. Westwood, M.L.; Peters, J.L.; Rooney, T.P. Prevalence and Coinfection of Three Tick-Borne Pathogens in Questing Adult Blacklegged Ticks Ixodes scapularis (Vilas County, Wisconsin). Vector-Borne Zoonotic Dis. 2020, 20, 633-635. [CrossRef] [PubMed]

4. One Health I CDC, 13 September 2021. Available online: https://www.cdc.gov/onehealth/index.html (accessed on 14 September 2021).

5. CDC, "Lyme Disease Reported Cases by Age Group, United States, 2019 I CDC," Centers for Disease Control and Prevention, 29 April 2021. Available online: https://www.cdc.gov/lyme/datasurveillance/charts-figures-recent.html (accessed on 22 November 2021).

6. McDonald, M.M.; Zeigler-Hill, V.; Vrabel, J.K.; Escobar, M. A Single-Item Measure for Assessing STEM Identity. Front. Educ. 2019, 4, 78. [CrossRef]

7. Irwin, A. No PhDs needed: How citizen science is transforming research. Nature 2018, 562, 480-482. [CrossRef] [PubMed]

8. Seifert, V.A.; Wilson, S.; Toivonen, S.; Clarke, B.; Prunuske, A. Community Partnership Designed to Promote Lyme Disease Prevention and Engagement in Citizen Science. J. Microbiol. Biol. Educ. 2016, 17, 63-69. [CrossRef] [PubMed]

9. National Academies of Sciences, Engineering, and Medicine, Division of Behavioral and Social Sciences and Education, Board on Science Education, and Committee on Designing Citizen Science to Support Science Learning, Learning Through Citizen Science: Enhancing Opportunities by Design; National Academies Press: Washington, DC, USA, 2018. Available online: http://www.ncbi.nlm.nih. gov/books/NBK535962/ (accessed on 14 September 2021).

10. Harris, M.A.; Grange, S.J.; Feeney, A.K.; Odorico, S.K. Undergraduate Students Are the Key to Community Science Outreach Partnerships. Test. Stud. Lab. Teach. 2018, 39, 1-7.

11. Biomeme I Take Real-Time PCR Everywhere You Need It.TM," Biomeme. Available online: https://biomeme.com/ (accessed on 28 September 2021).

12. Avoiding Contamination-US. Available online: //www.thermofisher.com/us/en/home/life-science/pcr/real-time-pcr/realtime-pcr-learning-center/real-time-pcr-basics/good-laboratory-practice-avoid-contamination-qpcr-experiments.html (accessed on 2 October 2021).

13. Stauffer, M.T.; Mandli, J.; Pritt, B.S.; Stauffer, W.; Sloan, L.M.; Zembsch, T.; Lee, X.; Paskewitz, S.M. Detection of zoonotic human pathogens from Ixodes scapularis in Wisconsin. J. Vector Ecol. 2020, 45, 147-149. [CrossRef] [PubMed]

14. Saw, G.K.; Agger, C.A. STEM Pathways of Rural and Small-Town Students: Opportunities to Learn, Aspirations, Preparation, and College Enrollment. Educ. Res. 2021, 50, 595-606. [CrossRef]

15. Roche, J.; Bell, L.; Galvão, C.; Golumbic, Y.N.; Kloetzer, L.; Knoben, N.; Laakso, M.; Lorke, J.; Mannion, G.; Massetti, L.; et al. Citizen Science, Education, and Learning: Challenges and Opportunities. Front. Sociol. 2020, 5. [CrossRef] [PubMed]

16. Understanding RT-PCR Tests and Results, National Collaborating Centre for Infectious Diseases, 12 February 2021. Available online: https://nccid.ca/publications/understanding-rt-pcr-tests-and-results/ (accessed on 2 October 2021).

17. Kopsco, H.L.; Xu, G.; Luo, C.-Y.; Rich, S.M.; Mather, T.N. Crowdsourced Photographs as an Effective Method for Large-Scale Passive Tick Surveillance. J. Med. Entomol. 2020, 57, 1955-1963. [CrossRef]

18. Hayes, M.; Smith, P.S.; Midden, W.R. Students as Citizen Scientists: It's Elementary. Sci. Child. 2020, 57, 60-64. 
19. Wagler, R.; Wagler, A. Fear and Disgust of Spiders: Factors that Limit University Preservice Middle School Science Teachers. Insects 2018, 9, 12. [CrossRef] [PubMed]

20. Knippenberg, M.T.; Leak, A.; Disseler, S.; Segarra, V.A. Establishing Partnerships for Science Outreach Inside and Outside the Undergraduate Classroom. J. Microbiol. Biol. Educ. 2020, 21, 20. [CrossRef] [PubMed] 